\title{
Capsaicin-Induced Apoptosis in MBT-2 Murine Bladder Tumor Cells and Bladder Wall Penetration Effect of the Nano-Encapsulated Capsaicin in Rabbit
}

\author{
Shin Jay Cho, Hyong Woo Moon, Woong Jin Bae, Yong-Hyun Park, \\ U-Syn Ha, Sung-Hoo Hong, Sae Woong Kim, Ji Youl Lee
}

Department of Urology, Seoul St. Mary's Hospital, College of Medicine,

The Catholic University of Korea, Seoul, Korea

\begin{abstract}
Purpose: In this study, we attempted to characterize capsaicin's effects with regard to the apoptosis of murine bladder cancer cells (MBT-2) as well as the pharmacodynamics of nano-encapsulated capsaicin formulation for intravesical instillation.

Materials and Methods: We assessed the viability of the MBT-2 cells via MTT staining, agarose gel electrophoresis, and flow cytometric apoptosis analysis. Intravesical reagents were instilled into 3 groups of male white New Zealand rabbits. Instillation agents were nano-encapsulated capsaicin dissolved in saline, capsaicin dissolved in saline, and capsaicin dissolved in dimethyl sulfoxide (DMSO). We also determined the pharmacokinetics of urine, plasma, and bladder tissue after intravesical capsaicin instillation.

Results: Capsaicin treatment was determined to reduce cell viability in a time- and dose-dependent manner. The capsaicin concentrations in the urine of the rabbits decreased in each of the treatment groups, but we noted a more profound reduction of capsaicin concentration in the nano-encapsulated capsaicin group. Plasma concentrations were definitely lower as compared with the levels measured in the bladder tissue and urine. We noted distinctive differences in patterns of concentration change between the capsaicin with normal saline solution (NSS) or DMSO and the nano-encapsulated capsaicin groups. The concentration of nano-encapsulated capsaicin in the tissue appeared to increase directly with tissue depth.

Conclusions: Our results show that capsaicin can induce apoptosis in MBT-2 cells, as well as the excellent permeation properties of nano-encapsulated capsaicin. Treatment with intravesical capsaicin may be a promising alternative therapeutic modality for the treatment of bladder cancer. (Korean J Urol Oncol 2019;17:168-177)
\end{abstract}

Key Words: Capsaicin $\cdot$ Bladder neoplasm $\cdot$ Intravesical treatment

Received October 10, 2019, Revised October 25, 2019,

Accepted October 28, 2019

Corresponding Author: Ji Youl Lee

Department of Urology, Seoul St. Mary's Hospital, The Catholic

University of Korea, 222 Banpo-daero, Seocho-gu, Seoul 06591,

Korea

E-mail: uroljy@catholic.ac.kr

Tel: +82-2-2258-6230, Fax: +82-2-2258-1401

ORCID: https://orcid.org/0000-0001-6775-1157

\section{INTRODUCTION}

Bladder cancer is the most frequently encountered urological malignancy in Korea. Approximately $70 \%$ of newly diagnosed bladder cancers are superficial variants (Ta, T1, or Tis). ${ }^{1}$ The normal treatment regimen for these superficial bladder cancers includes a transurethral resection for the removal of any visible tumors, coupled with subsequent intravesical therapy. This technique has been widely considered

This is an Open Access article distributed under the terms of the Creative Commons Attribution Non-Commercial License (http://creativecommons.org/licenses/by-nc/4.0/) which permits unrestricted non-commercial use, distribution, and reproduction in any medium, provided the original work is properly cited. 2019 (C) Copyright The Korean Urological Oncology Society and The Korean Prostate Society. All Rights Reserved. 
to be the most effective method for the prevention of bladder cancer recurrence, as well as the aggravation to invasive bladder cancer. Intravesical chemotherapy has the decided advantage of being able to selectively deliver high concentrations of drugs to the tumor-bearing bladder, while minimizing overall systemic exposure. Intravesical bacillus Calmette-Guerin (BCG) constitutes the main treatment modality currently used in cases of superficial bladder cancer. However, $30 \%-40 \%$ of treated patients fail to respond to $\mathrm{BCG}$, and another $30 \%-40 \%$ of initial responders experience a relapse within 5 years. BCG has also been associated with possibly severe complications, including fever, granulomatous prostatitis, hematuria pneumonia, sepsis, and hypersensitivity.

In previous studies, a host of intravesical chemotherapeutic agents have been assessed, and many have been shown to reduce short-term recurrence rates. However, none have proven effective for preventing long-term recurrence rates or tumor progression. Several studies have reported BCG's superior efficacy as compared to mitomycin $\mathrm{C}$ and doxorubicin. ${ }^{2-5}$

Several studies have also indicated that the failure mitomycin $\mathrm{C}$ and doxorubicin treatments are attributable, in part, to the inability of the drugs to penetrate bladder tissue and also to the low activity of these drugs when pitted against more aggressive tumors. ${ }^{6-10}$ Enhanced drug delivery was shown to improve treatment outcomes in a phase III trial, which demonstrated that the augmentation of mitomycin $\mathrm{C}$ delivery resulted in a recurrence-free rate nearly double previous levels in superficial bladder cancer patients. ${ }^{11}$

Taken together, these findings show that the 2 most important properties of a drug to be used in intravesical therapy are its activity against bladder cancer and its ability to penetrate bladder tissues. As discussed below, capsaicin appears to be an attractive candidate for such use.

Capsaicin (trans-8-methyl-N-vanillyl-6-nonenamide), the primary acrid compound in the red pepper, has been applied in food ingredients and drugs for quite a long time. Recently, an attempt was made to use capsaicin as an intravesical drug for the treatment of detrusor hyperreflexia in overactive bladder. ${ }^{12}$ Capsaicin has also been demonstrated to impair growth and cause apoptosis in vitro in a variety of transformed cell types, but this was not found in normal counterpart cells. ${ }^{13-16}$ Furthermore, these compounds re- portedly promote apoptosis in vivo as the mechanism underlying tumor cell elimination in animal carcinogenesis models. ${ }^{17}$ In particular, studies have shown that in certain bladder cells capsaicin induces cell cycle arrest, apoptosis, and decreased cell migration. ${ }^{18}$

Chemically, capsaicin features an aromatic ring, an amide bond, and a hydrophobic side chain in its structure, which renders it an extremely hydrophobic molecule that is insoluble in water. Therefore, for intravesical application, capsaicin is normally incorporated with normal saline solution (NSS) and 30\% ethanol. ${ }^{19}$ However, this vehicle has been reported to exacerbate the adverse histological changes associated with capsaicin, including epithelial thinning and submucosal edema. ${ }^{20}$ Thus, better and safer vehicles for water-insoluble capsaicin are clearly a prerequisite for the development of an effective delivery protocol.

In order to improve the delivery of the extremely hydrophobic capsaicin, we decided to encapsulate it within a hydrophobic polymer matrix. Therefore, we selected polylactic acid-polyglycolic acid (PLGA) copolymer and poly(ethylene oxide)-poly(propylene oxide)-poly(ethylene oxide) (Pluronic F-127) as materials for the encapsulation. ${ }^{21}$

In the present study, in order to assess the possibility of utilizing nano-encapsulated capsaicin in an intravesical therapeutic strategy in cases of superficial bladder cancer, we have attempted to determine (1) whether capsaicin is able to induce apoptosis in bladder tumor cells, applying the MBT-2 murine bladder tumor cell line, and (2) the pharmacodynamics of our nano-encapsulated capsaicin formulation with regard to intravesical instillation in rabbits, in order to assess the possibility of utilizing nano-encapsulated capsaicin in an intravesical therapeutic strategy in cases of superficial bladder cancer.

\section{MATERIALS AND METHODS}

\section{The Effect of Capsaicin on MBT-2 Cells}

\section{1) Cell culture}

MBT-2 cells were cultured on Rosewell Park Memorial Institute (RPMI) 1640 medium (Sigma, St. Louis, MO, USA) supplemented with $10 \%$ fetal bovine serum (Hyclone, Logan, UT, USA), 2.0-mg/mL sodium bicarbonate, $10 \mathrm{mM}$ HEPES, 100-units/mL penicillin, and $100-\mu \mathrm{g} / \mathrm{mL}$ streptomycin at $37^{\circ} \mathrm{C}$ in a humidified atmosphere containing $5 \% \mathrm{CO}_{2}$. 
The cells were split via trypsinization in a 1:3 ratio every other day.

\section{2) Cell viability assay}

Cell viability was evaluated via 3-(4,5-dimethylthiazol-2-yl)-2,5-diphenyltetrazolium bromide (MTT) assays on the basis of the decreased amount of MTT into formazan dye as the result of mitochondrial activity. ${ }^{22}$ In brief, the cells were cultured with the determined drug concentrations in $100-\mu \mathrm{L}$ RPMI 1640 medium for 48 hours, at an initial cell density of $5 \times 10^{3}$ cells $/ \mathrm{cm}^{2}$. Then, $10 \mu \mathrm{L}$ MTT solution (5-mg MTT/mL in phosphate-buffered saline [PBS]) was added to each of the wells of the microtiter plates, and incubated for another 4 hours. After washing, the formazan dye solidifies, the extent of which was proportional to the number of live cells, were liquefied in $200-\mu \mathrm{L}$ dimethyl sulfoxide (DMSO). Absorbance was observed at $540 \mathrm{~nm}$ with an enzyme-linked immunosorbent assay reader (Molecular Devices, Downingtown, PA, USA).

\section{3) DNA fragmentation detection}

Following incubation, the cell that were either treated with or without capsaicin, were harvested via centrifugation at $400 \times \mathrm{g}$ for 5 minutes, washed twice in PBS $(\mathrm{pH}, 7.4)$, then resuspended in $800 \mu \mathrm{L}$ of lysis buffer consisting of 5 $\mathrm{mM}$ Tris, $0.5 \%$ Triton $\mathrm{X}-100$, and $10 \mathrm{mM}$ ethylenediaminetetraacetic acid (EDTA) $(\mathrm{pH}, 8.0)$. The cell suspensions were then incubated for 30 minutes on ice and pelleted via centrifugation $\left(13,000 \times \mathrm{g}\right.$ for $20 \mathrm{~min}$ at $\left.4^{\circ} \mathrm{C}\right)$. The supernatants were then incubated with $8-\mu \mathrm{L}$ RNase A (10 $\mathrm{mg} / \mathrm{mL}$ ) for an additional 1 hour at $37^{\circ} \mathrm{C}$. After this incubation, $8-\mu \mathrm{L}$ proteinase $\mathrm{K}(10 \mathrm{mg} / \mathrm{mL})$ was mixed, and incubation resumed for one more hour at $37^{\circ} \mathrm{C}$. The cellular DNA was then separated using phenol:chloroform (1:1) and centrifuged at $13,000 \times \mathrm{g}$ for 10 minutes, after which $800-\mu \mathrm{L}$ isopropanol retaining $0.3 \mathrm{M}$ sodium acetate was added. This solution was then pelleted via centrifugation $(13,000 \mathrm{~g}$ for 15 minutes at $4{ }^{\circ} \mathrm{C}$ ). The extracted and purified DNA was liquefied in loading buffer $(2.5 \%$ Ficoll, $20 \mathrm{mM}$ EDTA, $0.04 \%$ bromophenol blue, $1.8 \%$ xylene cyanol FF) and electrophoresed on $1.8 \%$ agarose gel in TBE buffer $(45 \mathrm{mM}$ Tris-borate, $1 \mathrm{mM}$ EDTA) at $50 \mathrm{~V}$, then it was formed visually by staining with $0.5-\mu \mathrm{g} / \mathrm{mL}$ ethidium bromide.

\section{4) Flow cytometric analysis}

In order to confirm the extent and rate of apoptosis, the cells were then stained with propidium iodide as previously described. ${ }^{23}$ The cells were then examined applying flow cytometric analysis using the FACSCalibur system (BectonDickinson, Franklin Lakes, NJ, USA) equipped with the Cell Quest program.

\section{5) Statistical analysis}

Two-tailed Student t-tests were used in order to examine the significance of the tested data. The data were demonstrated as the means \pm SEM. Values of $\mathrm{p}<0.05$ were considered to be significant.

\section{The Pharmacodynamics of the Nano-Encapsulated Capsaicin}

\section{1) Materials}

Pluronic F-127 can be represented by the formula poly (ethylene oxide)-poly(propylene oxide)-poly(ethylene oxide), based on its nominal molecular weight of 12600 and $75 \%$ PEO content. The PLGA copolymer $(75 \mathrm{~mol} \%$ of lactide, Molecular weight: 90,000) was purchased from Boelinger Ingelheim (Ingelheim, Germany). The tetraglycol, Tween 80, and capsaicin were purchased from Sigma.

\section{2) Preparation of Capsaicin-Loaded PLGA Nanoshperes}

Ten $\mathrm{ml} \mathrm{PLGA/tetraglycol} \mathrm{solution} \mathrm{was} \mathrm{prepared} \mathrm{sepa-}$ rately by mixing PLGA with tetraglycol. Then, $0.5 \%$ (by weight) Tween 80 was added to the total amount of PLGA as an emulsifier. This solution was then sprayed into $100-\mathrm{mL}$ water, in order to induce the precipitation of PLGA in a nanospheric form. After the formation of the PLGA nanospheres, dialysis was conducted for the removal of the tetraglycol. In order to complete the drug loading, $50 \mathrm{ml}$ of ethanol-capsaicin solution was added to the dialyzed aqueous media. Drug loading was then carried out via the evaporation of ethanol in a vacuum oven at $25^{\circ} \mathrm{C}$ for 48 hours, and the atmosphere in the vacuum oven was replaced every 6 hours with clean air. During the initial stage of drug loading, the capsaicin was loaded by adsorption into the PLGA nanospheres. Finally, 10-mL pluronic F-127 aqueous solution was poured into the solution mixture containing the capsaicin-adsorbed PLGA nanospheres. This solution mix- 
ture was then freeze-dried to induce pluronic F-127 in order to stabilize the capsaicin-adsorbed PLGA nanospheres. All of the above-mentioned manufacturing steps were conducted by the Department of Polymer Science \& Engineering Chemical Delivery Polymers Laboratory.

\section{3) Animal study}

This study was performed with 15 male white New Zealand rabbits, each weighing between 2-3 kg (Changddul, Gwangju, Korea). These rabbits were given access to both water and feed ad libitum. The rabbits were exposed to light from $7 \mathrm{AM}$ to $6 \mathrm{PM}$, and their environment was maintained at a temperature of $22^{\circ} \mathrm{C}-24^{\circ} \mathrm{C}$ and a humidity of $40 \%-60 \%$. The rabbits were anesthetized via intramuscular injection of a $0.7-\mathrm{mL} / \mathrm{kg}$ mixture of ketamine $(25 \mathrm{mg} / \mathrm{mL})$ and xylazine $(20 \mathrm{mg} / \mathrm{mL})$, and they remained under anesthesia throughout the experiment. A 24-gauge intravenous Teflon catheter (Instyle-WR, Becton Dickinson, Heidelberg, Germany) was placed into the marginal ear vein to stabilize the intravenous line, from which the blood samples were extracted. After the external genitalia were sterilized, a $10 \mathrm{~F}$ urethral catheter was inserted, and ballooning was performed within the bladder using 3-mL distilled water. The urine was gathered using the inserted urethral catheter. All of the tests took place between $8 \mathrm{AM}$ and $11 \mathrm{AM}$. After the bladder had been emptied by the collection of urine via the inserted urethral catheter, the drugs were introduced through the same catheter.

The intravesical reagents were instilled in 3 groups of female white New Zealand rabbits. We used the following combinations intravesical agents in this study: (1) nano-encapsulated capsaicin dissolved in saline $(30 \mu \mathrm{M})$, (2) capsaicin dissolved in saline $(30 \mu \mathrm{M})$, and (3) capsaicin dissolved in DMSO $(30 \mu \mathrm{M})$. The volume of intravesical instillation was $20 \mathrm{~mL}$ for each capsaicin formulation.

After the drugs had been instilled, the blood and urine samples were regularly taken both before and after drug injection, and until the bladder was extracted. A $10-\mathrm{mL}$ syringe was inserted into the end of the urethral catheter for urine collection. This syringe was used to collect an initial $5-\mathrm{mL}$ urine, to ensure that the urine would fully fill the catheter. Then, a 1-mL syringe and a 30-gauge needle were used to take $100-\mu \mathrm{L}$ urine samples via the perforating of the catheter. Any residual urine within the catheter was sent back into the bladder. Urine collection was performed within 2 minutes in all cases.

The drugs were permitted to remain inside the bladder for 120 minutes. After 120 minutes of treatment, the bladder was extracted dissecting the central line of the abdomen.

\section{4) Pharmacodynamics}

\section{(1) Capsaicin concentration changes in urine}

Shifts in the capsaicin concentration within the urine were evaluated in order to observe the pharmacodynamic changes occurring after the injection of drugs into the bladder. Urine was taken every 10 minutes during the initial 30 minutes of drug injection, every 15 minutes during the next 30 minutes (twice), and every 30 minutes afterward, for 120 minutes. These collected urine samples were promptly frozen with liquid nitrogen. The capsaicin concentration was measured in each of these samples using high-pressure liquid chromatography (HPLC). ${ }^{24}$

\section{(2) Capsaicin concentration changes within the blood}

Shifts in capsaicin concentration were examined in order to measure pharmacodynamic changes in the drugs infused into the blood stream after their absorption into the bladder tissues. As was the case with the urine samples, the blood samples were collected every 30 minutes for 120 minutes. The collected blood samples were also frozen immediately with liquid nitrogen. The plasma capsaicin concentrations, however, were so extremely low that we used competitive inhibition enzyme immunoassay, with a measurement limit of $0.2 \mathrm{ng} / \mathrm{mL}$.

\section{(3) Capsaicin concentrations in bladder tissue}

Frozen bladder wall tissue samples were carved, parallel to the urothelial surface, into $50-\mu \mathrm{m}$ slices using a cryotome (Carl ZEISS, Thorn-wood). Preweighed tissue samples were vortex-mixed with $30-\mu \mathrm{L}$ internal standard (margaric acid, $2.01 \mathrm{mg} / \mathrm{mL}$ ) and $1-\mathrm{mL}$ chloroform, until all of the tissue floated loosely in solution. This compound was quantitatively relocated to $15-\mathrm{mL}$ nalgene culture tubes. An additional 4-mL chloroform was then mixed. This mixture was incubated at $37^{\circ} \mathrm{C}$ with continuous shaking for 120 minutes, and supplemented with vortex-mixing every 15 minutes. After 15 minutes of centrifugation at $2,000 \times \mathrm{g}$ at $4{ }^{\circ} \mathrm{C}$, the aqueous supernatant was extracted by suction and removed. The remaining organic layer was then quantitatively moved to a $10-\mathrm{mL}$ glass tube. The residue compound was recon- 
stituted in $200 \mu \mathrm{L}$ methanol/acetonitirile/water (72:13:15), and $100 \mu \mathrm{L}$ of the reconstructed derivatized product was analyzed via HPLC. The first sections were abandoned, in order to dismiss any tissue contamination due to urine. The next 8 sections were then individually analyzed, whereas the latter sections were pooled for analysis as they contained lower drug concentrations.

\section{5) Statistical analysis}

We employed 1-way analysis of variance tests and post hoc multiple comparisons in order to evaluate the significance of the data. The data were expressed as means \pm

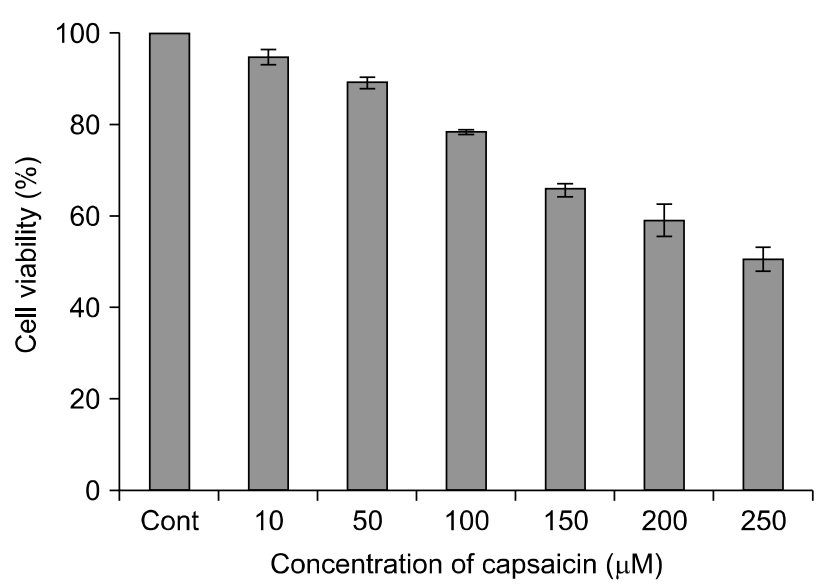

Fig. 1. MBT-2 cells were treated for 48 hours with or without each concentration of Capsaicin. Capsaicin decreased cell viability in dose dependent manner analyzed by MTT assay. standard error of the mean. Values of $p<0.05$ were considered to be significant.

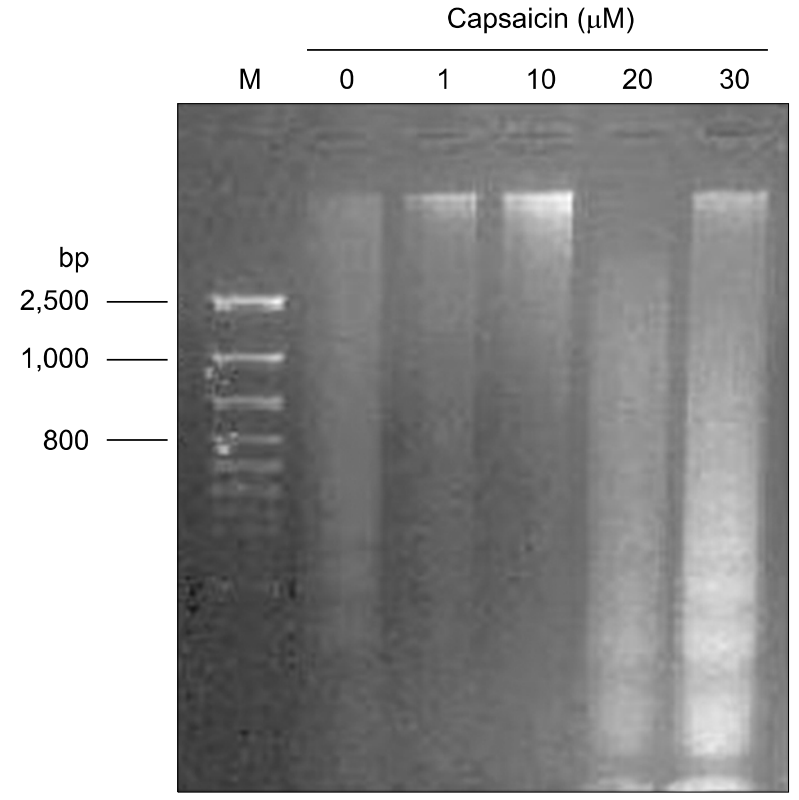

Fig. 2. MBT-2 cells were treated for 48 hours with or without each concentration of Capsaicin. DNA was isolated from the cells and analyzed by $1.8 \%$ agarose gel electrophoresis. Lane $\mathrm{M}$ represents DNA marker.
A

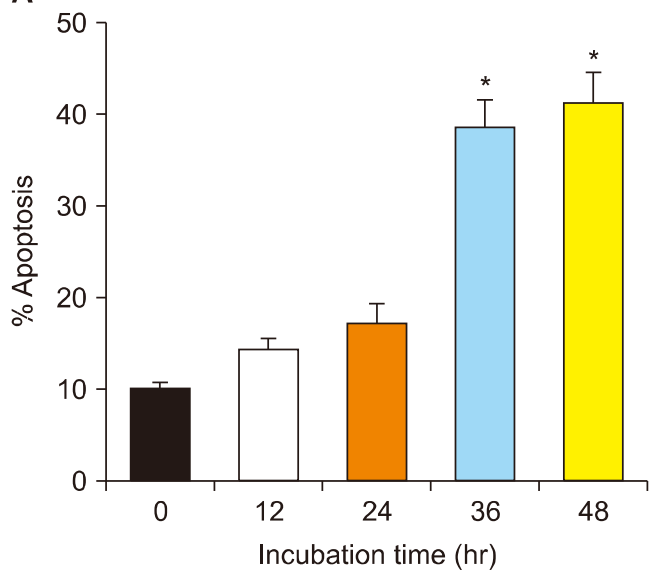

B

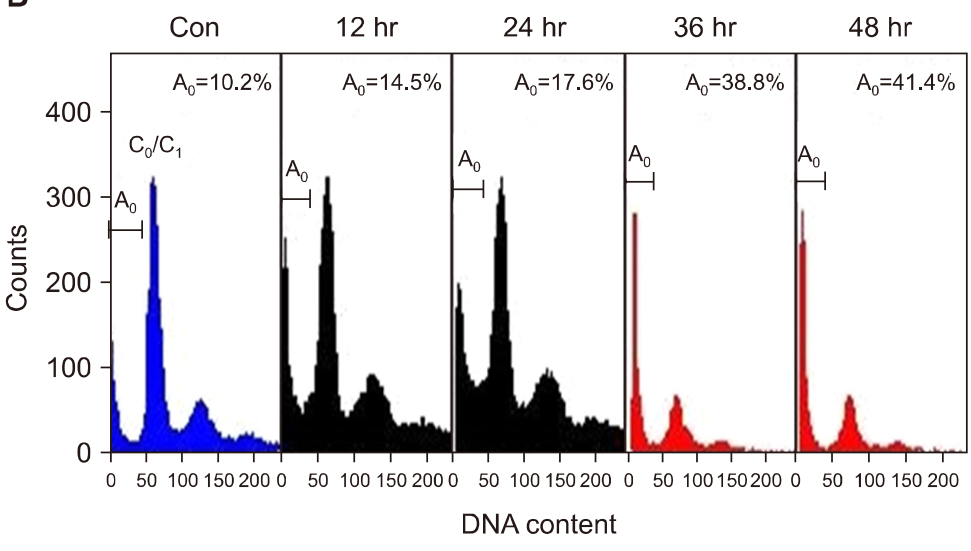

Fig 3. MBT-2 cells were treated with Cap $(100 \mu \mathrm{M})$ for each designated time. Cells were stained with propium iodide, and the number of apoptotic cells was measured by flow cytometry. (A) Capsaicin $(100 \mu \mathrm{M})$ was shown to induce apoptosis in a time-dependent manner, according to the results of flow cytometry. In bar graphs the data represent the mean values of 4 replications with bars indicating standard error of the mean. ${ }^{*} p<0.05$. (B) The region to the left of the Go/G1 peak, designated Ao, was defined as cells undergoing apoptosis-associated DNA degradation. 


\section{RESULTS}

\section{The Effects of Capsaicin in MBT-2 Cells}

Capsaicin's effects on the viability of MBT-2 cells were determined via MTT staining. Capsaicin was found to reduce cell viability in a dose-dependent manner (Fig. 1). Capsaicin began to evidence significant cytotoxicity at a concentration of $100 \mathrm{mM}$. In order to determine the extent to which capsaicin induced apoptotic cell death in MBTmurine bladder cancer cells, we conducted 2 independent measurements, using agarose gel electrophoresis and flow cytometry. We determined that capsaicin induced a dose-dependent DNA fragmentation - a hallmark of apoptosis - as demonstrated by the results of agarose gel electrophoresis (Fig. 2). Furthermore, capsaicin $(100 \mu \mathrm{M})$ was also shown to induce apoptosis in a time-dependent manner, according to the results of flow cytometry, in which the hypodiploid DNA content was determined via propidium iodine staining (Fig. 3). These results demonstrate that capsaicin exerts an apoptosis-inducing effect in MBT-2 human bladder cancer cells.

\section{Pharmacodynamics of Nano-Encapsulated Capsaicin}

\section{1) Changes in urine capsaicin concentration}

Fig. 4A depicts the decrease in urine capsaicin concentration against the function of instillation time. The down-
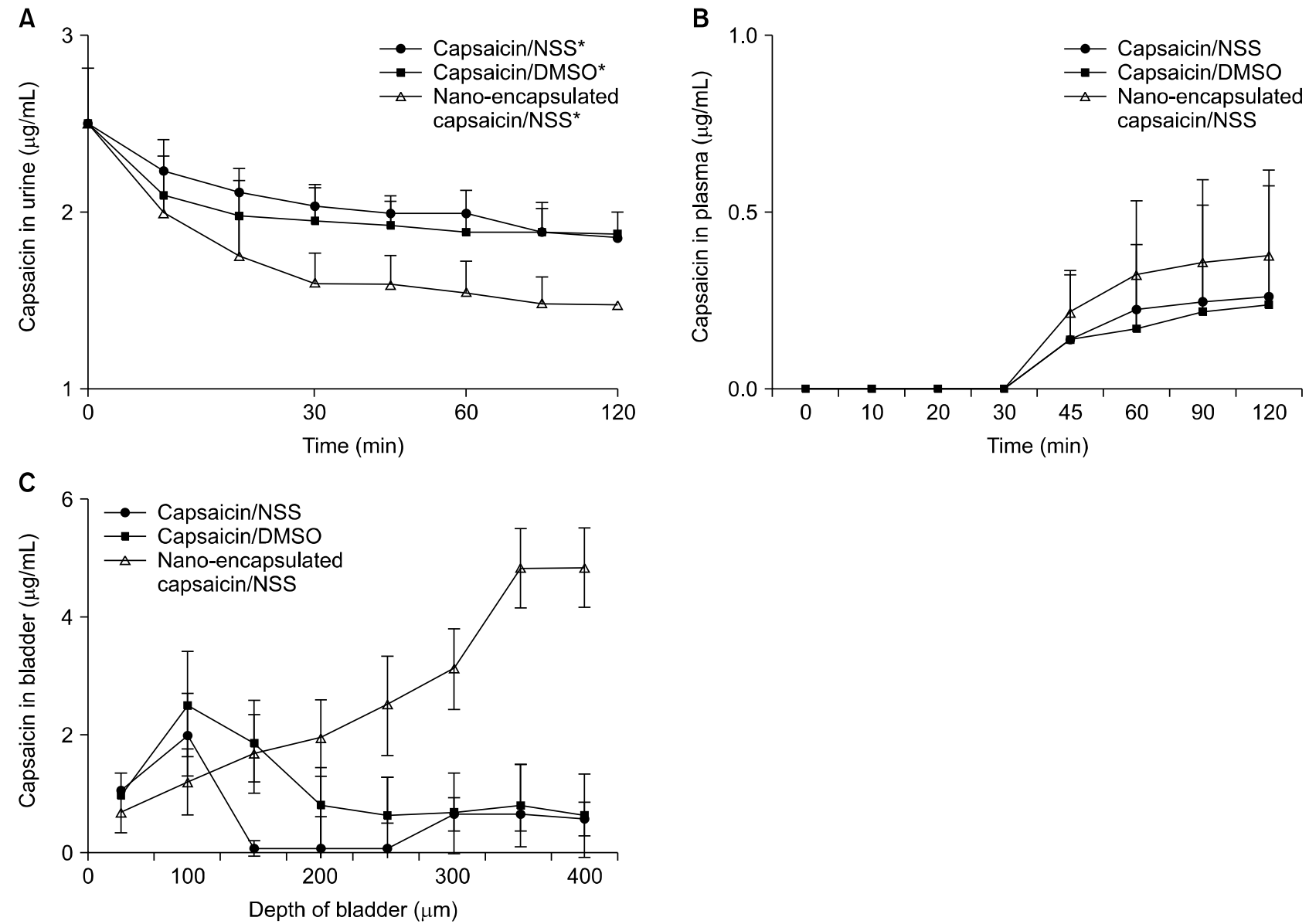

Fig. 4. (A) Concentration of urine capsaicin during intravesical instillation for 120 minutes. The data point at zero time is the concentration in the dosing solution; the later data points represent the concentration in urine samples obtained serially from the bladder. Values in each group are means \pm standard deviation (SD) $(n=5) .{ }^{*} \mathrm{p}<0.05$, among groups. (B) Concentration of plasma capsaicin during intravesical instillation for 120 minutes. Plasma concentrations through time. Values in each group are means $\pm \mathrm{SD}$ $(n=5)$. (C) Tissue concentration-depth profiles of capsaicin in bladder tissue after the 120-minute treatment. The concentration change pattern among capsaicin with NSS or DMSO and nano-encapsulated capsaicin was very distinctive. The concentration of nano-encapsulated capsaicin in tissue increased with tissue depth. Values in each group are means $\pm \mathrm{SD}(\mathrm{n}=5)$. 
Table 1. The phramacodynamics of capsaicin at 120 minutes

\begin{tabular}{lccc}
\hline \multicolumn{1}{c}{ Variable } & $\begin{array}{c}\text { Capsaicin } \\
\text { /NSS }\end{array}$ & $\begin{array}{c}\text { Capsaicin } \\
\text { /DMSO }\end{array}$ & $\begin{array}{c}\text { Nano- } \\
\text { encapsulated } \\
\text { capsaicin/NSS }\end{array}$ \\
\hline $\mathrm{C}_{\max }(\mu \mathrm{g} / \mathrm{mL})$ & 2.00 & 2.54 & 4.88 \\
$\mathrm{C}_{\mathrm{u}}(\mu \mathrm{g} / \mathrm{mL})$ & 1.85 & 1.87 & 1.45 \\
$\mathrm{C}_{\max } ; \mathrm{C}_{\mathrm{u}}$ & 1.08 & 1.36 & 3.37 \\
Weight of dried & 51.0 & 58.2 & 119.0 \\
sample at $\mathrm{C}_{\max }(\mu \mathrm{g})$ & & & \\
Depth at $\mathrm{C}_{\max }(\mu \mathrm{m})$ & 100 & 100 & 400 \\
\hline
\end{tabular}

$\mathrm{C}_{\max }$ indicates highest concentration of capsaicin. $\mathrm{C}_{\text {uro }}$ indicates drug concentration from urothelial surface to about 50$\mu \mathrm{m}$ depth. $\mathrm{C}_{\mathrm{u}}$ is urine concentration at 120 minutes. NSS: normal saline solution, DMSO: dimethyl sulfoxide.

ward trend in urine concentration from zero time to $10 \mathrm{mi}$ nutes reflects the dilution of capsaicin by residual urine in the bladder. As the therapy progressed, continuing urine accumulation also effected an increased dilution, and hence a further decrease in the concentration of the drug. We also noted a significant difference between the capsaicin dissolved in NSS or DMSO and the nano-encapsulated capsaicin after 30 minutes of treatment $(p<0.001)$. The nanoencapsulated capsaicin concentration declined at a more rapid rate than did the concentrations of the NSS or DMSOdissolved capsaicin.

\section{2) Capsaicin concentration changes within the blood}

Capsaicin concentrations within the plasma were determined to increase over time, but these concentrations remained extremely low overall (Fig. 4B). We found no significant differences among the experimental groups in this regard $(\mathrm{p}>0.3)$.

\section{3) Capsaicin concentrations in bladder tissue}

Fig 4C depicts the concentration-depth profiles of capsaicin within the bladder tissues. Table 1 describes the pharmacokinetic parameters of the tissues. The concentration of the NSS or DMSO-dissolved capsaicin in the tissue declined exponentially as the drug flowed through the loosely packed, capillary-perfused connective tissue. However, the concentration of the nano-encapsulated capsaicin increased directly with the depth of the tissue, a tendency which was not observed with the nonencapsulated capsaicin. The maximal ratios of urothelial capsaicin concentration to urine capsaicin concentration $\left(\mathrm{C}_{\max } ; \mathrm{C}_{\mathrm{u}}\right)$ were determined to be 1.08 for the capsaicin dissolved in saline, 1.36 for capsaicin dissolved in DMSO, and 3.37 for the nano-encapsulated capsaicin dissolved in saline. We detected significant differences between the concentrations patterns of the capsaicin dissolved in NSS or DMSO and the nano-encapsulated capsaicin $(\mathrm{p}<0.001)$.

\section{DISCUSSION}

In multicellular organisms, differentiated cells apparently share the ability to induce their own death via the activation of an internally encoded suicide program, which is commonly referred to as apoptosis. Apoptosis is arguably the most potent natural defense against the development of cancer. Therefore, many attempts have been made to develop a chemoprevention strategy that selectively triggers apoptosis in both malignant and premalignant cancer cells. In this study, we have evaluated the possibility of using capsaicin as a new intravesical agent for the treatment of superficial bladder cancer. Capsaicin is the principal active component of the hot chili pepper, Capsicum. Spicy foods have been loosely implicated in carcinogenesis in humans, but, thus far, only a single epidemiological study has demonstrated the correlation between the consumption of hot chili peppers and the incidence of gastric cancer. ${ }^{25}$ However, several studies have reported the observation of capsaicin's tumor-initiating or -promoting potential, and other studies have demonstrated capsaicin's chemoprotective effects. ${ }^{26-30}$ Moreover, capsaicin has been reported to inhibit the cellular growth of neuroblastoma and hepatocarcinoma cells, as well as human glioblastoma cells, via apoptotic induction. As mentioned above, recent studies have demonstrated that capsaicin possesses at least some anticancer potential. $^{31-33}$

The mechanism underlying capsaicin-induced apoptosis remains unclear. But recently, there have been reports demonstrating anticancer effects of capsaicin on certain bladder cancer cells. Experiments revealed that a cancer associated phenotype, tumor-associated NADH oxidase (tNOX) was inhibited by capsaicin reducing NADH to $\mathrm{NAD}^{+}$oxidation. This downregulated sirtuin 1 (SIRT1), a deacetylase which regulates cell functions, resulting in reduced bladder cancer cell phenotypes, by apoptosis and cell cycle arrest. ${ }^{34,35}$ 
Recent reports on the subject have produced controversial or conflicting results as well, and the effects of capsaicin on human bladder tumor cells have yet to be adequately elucidated.

The present study demonstrated that treatment with capsaicin markedly induced apoptosis in a time- and dose-dependent manner in MBT-2 cells measured by DNA ladder formation and flow cytometric analysis of hypodiploid DNA stained with propidium iodide.

These results show that capsaicin induces apoptosis in MBT-2 cells, and suggest that capsaicin may be useful for the treatment of human bladder cancers.

According to above results, capsaicin may be an attractive alternative. For this hydrophobic-natured capsaicin to act as an agent with anticancer potential in in vivo bladder tumors, an appropriate vehicle (with the property as solvent for drugs to be intravesically instilled and property of permeating into bladder transitional epithelium) is indispensable. Additionally, this vehicle must manifest the characteristic of causing minimal damage to the normal bladder mucosa and minimal absorption into the vascular system to minimize the systemic toxicity.

The currently accepted vehicle for intravesical capsaicin is ethanol in saline due to the hydrophobic nature of capsaicin. ${ }^{19}$ Unfortunately, in a study in spinal cord injured patients, the ethanol vehicle alone was observed to be just as irritating to the bladder mucosa as capsaicin. ${ }^{36}$ The pain and autonomic dysreflexia reported by some patients during and sometimes after instillations have hindered the wider application of the clinical use of intravesical capsaicin. Previous reports showed that the alcoholic vector was the major cause of poor instillation tolerability. ${ }^{37}$ The undesirable use of ethanol to dissolve capsaicin made the current investigate alternative vehicle to NSS. In this study, we attempted to characterize the pharmacodynamics of nanoencapsulation in the construction of a capsaicin vehicle, using rabbits as an experimental model. Two different materials, PLGA and pluronic F-127, were used in this study as nano-encapsulation materials for the loading of capsaicin in this study. PLGA, which has been shown to possess both biocompatible and biodegradable properties, has been used extensively in biomedical and pharmaceutical applications for the control of drug delivery. Pluronic F-127, a triblock thermosensitive copolymer, exists as a free-flowing solution at room temperature and transforms to a gel at body temperature. ${ }^{38}$ These rheological properties render the polymer eminently suitable for use in the intravesical administration of capsaicin. Interestingly, we found in this study that the concentration of nano-encapsulated capsaicin in the tissues increased directly with the depth of the tissues, although the concentration of capsaicin dissolved in NSS or DMSO in the tissue declined. As shown in Fig. 4B and Table 1, capsaicin concentrations increased with tissue depth in the experimental group which had been treated with the nano-encapsulated capsaicin. In addition, the maximal ratio of urothelial capsaicin concentration to urine capsaicin concentration $\left(\mathrm{C}_{\max } ; \mathrm{C}_{\mathrm{u}}\right)$ was found to be higher in the nano-encapsulated experimental group than in the other groups. These results indicate that nano-encapsulation improves the rate at which the capsaicin permeates the tissues of the bladder. The amphiphilic nature of the polymer used for encapsulation in this study might have facilitated the permeation of the drug through the bladder mucosal epithelium, which indicates the bioadhesive properties of the PEO-PPO-PEO triblock polymer, which assumes a gel form at body temperature.

By comparing the changes in the capsaicin concentrations between the groups, we were able to observe a more distinctive decline in the urine capsaicin concentration in the nano-encapsulated experimental group than in the other groups. Comparisons of the plasma capsaicin concentrations, which were conducted in order to evaluate systemic toxicity, revealed no significant difference in plasma capsaicin concentrations between groups. This result can be interpreted to mean that the nano-encapsulated capsaicin, which, according to the aforementioned results, was more effective than other preparations with regard to the permeation of the bladder tissue, exhibits no more systemic vascular infiltration ability than does the nonencapsulated capsaicin. The above finding may provide us with the means to develop a new and effective alternative vehicle for capsaicin instillation.

Before the present study, there had been no definitive histopathological analyses of the changes in bladder mucosa as the result of intravesical capsaicin application. In a previous study, it was demonstrated that acute damage to urothelial integrity was more profound in rats treated with capsaicin in ethanol than in the rats which had been treated 
solely with an ethanol vehicle. However, the urothelial tissue in these rats returned to normal within a few days. ${ }^{39}$

Hence, we conclude that the intravesical instillation of nano-encapsulated capsaicin may constitute a promising alternative therapeutic modality, and the further evaluation of the properties and efficacy of nano-encapsulated capsaicin in superficial bladder tumor models is clearly warranted.

\section{CONFLICT OF INTEREST}

The authors claim no conflicts of interest.

\section{REFERENCES}

1. Malkowicz SB. Management of superficial bladder cancer. In: Walsh PC, Retik AB, Vaughan ED Jr, Wein AJ, Kavoussi LR, Novick AC, et al., editors. Campbell's urology. 8th ed. Philadelphia (PA): WB Saunders Co; 2002:2785-802.

2. Lamm DL, Blumenstein BA, Crawford ED, Montie JE, Scardino P, Grossman HB, et al. A randomized trial of intravesical doxorubicin and immunotherapy with bacille Calmette-Guérin for transitional-cell carcinoma of the bladder. N Engl J Med 1991;325:1205-9.

3. Traynelis CL, Lamm DL. Current status of intravesical therapy for bladder cancer. In: Rous SN, editor. Urology annual. vol. 8. New York: WW Norton and Co; 1994;11343.

4. Malmström PU, Wijkström H, Lundholm C, Wester K, Busch C, Norlén BJ. 5-year followup of a randomized prospective study comparing mitomycin $\mathrm{C}$ and bacillus Calmette-Guerin in patients with superficial bladder carcinoma. Swedish-Norwegian Bladder Cancer Study Group. J Urol 1999;161:1124-7.

5. Sylvester RJ, van der MEIJDEN AP, Lamm DL. Intravesical bacillus Calmette-Guerin reduces the risk of progression in patients with superficial bladder cancer: a meta-analysis of the published results of randomized clinical trials. J Urol 2002;168:1964-70.

6. Dalton JT, Wientjes MG, Badalament RA, Drago JR, Au JL. Pharmacokinetics of intravesical mitomycin $\mathrm{C}$ in superficial bladder cancer patients. Cancer Res 1991;51: 5144-52.

7. Schmittgen TD, Wientjes MG, Badalament RA, Au JL. Pharmacodynamics of mitomycin $\mathrm{C}$ in cultured human bladder tumors. Cancer Res 1991;51:3849-56.

8. Wientjes MG, Badalament RA, Wang RC, Hassan F, Au JL. Penetration of mitomycin $\mathrm{C}$ in human bladder. Cancer Res 1993;53:3314-20.
9. Chai M, Wientjes MG, Badalament RA, Burgers JK, Au JL. Pharmacokinetics of intravesical doxorubicin in superficial bladder cancer patients. J Urol 1994;152(2 Pt 1): 374-8.

10. Wientjes MG, Badalament RA, Au JL. Penetration of intravesical doxorubicin in human bladders. Cancer Chemother Pharmacol 1996;37:539-46.

11. Au JL, Badalament RA, Wientjes MG, Young DC, Warner JA, Venema PL, et al. Methods to improve efficacy of intravesical mitomycin C: results of a randomized phase III trial. J Natl Cancer Inst 2001;93:597-604.

12. De Ridder D, Chandiramani V, Dasgupta P, Van Poppel H, Baert L, Fowler CJ. Intravesical capsaicin as a treatment for refractory detrusor hyperreflexia: a dual center study with long-term followup. J Urol 1997;158:2087-92.

13. Jung MY, Kang HJ, Moon A. Capsaicin-induced apoptosis in SK-Hep-1 hepatocarcinoma cells involves Bcl-2 downregulation and caspase-3 activation. Cancer Lett 2001;165: 139-45.

14. Surh YJ. More than spice: capsaicin in hot chili peppers makes tumor cells commit suicide. J Natl Cancer Inst 2002;94:1263-5.

15. Kang HJ, Soh Y, Kim MS, Lee EJ, Surh YJ, Kim HR, et al. Roles of JNK-1 and p38 in selective induction of apoptosis by capsaicin in ras-transformed human breast epithelial cells. Int J Cancer 2003;103:475-82.

16. Zhang J, Nagasaki M, Tanaka Y, Morikawa S. Capsaicin inhibits growth of adult T-cell leukemia cells. Leuk Res 2003;27:275-83.

17. Tanaka T, Kohno H, Sakata K, Yamada Y, Hirose Y, Sugie $\mathrm{S}$, et al. Modifying effects of dietary capsaicin and rotenone on 4-nitroquinoline 1-oxide-induced rat tongue carcinogenesis. Carcinogenesis 2002;23:1361-7.

18. Qian K, Wang G, Cao R, Liu T, Qian G, Guan X, et al. Capsaicin suppresses cell proliferation, induces cell cycle arrest and ROS production in bladder cancer cells through FOXO3a-mediated pathways. Molecules 2016;21:1406-20.

19. Giannantoni A, Di Stasi SM, Stephen RL, Navarra P, Scivoletto G, Mearini E, et al. Intravesical capsaicin versus resiniferatoxin in patients with detrusor hyperreflexia: a prospective randomized study. J Urol 2002;167:1710-4.

20. Byrne DS, Das A, Sedor J, Huang B, Rivas DA, Flood $\mathrm{HJ}$, et al. Effect of intravesical capsaicin and vehicle on bladder integrity control and spinal cord injured rats. J Urol 1998;159:1074-8.

21. Alexandridis P, Hatton T. Poly(ethylene oxide)-poly(propylene oxide )-poly (ethylene oxide) block copolymer surfactants in aqueous solutions and at interfaces: thermodynamics, structure, dynamics, and modeling. Coll Surf A: Physicochem Eng Asp 1995;96:1-46.

22. Mosmann T. Rapid colorimetric assay for cellular growth and survival: application to proliferation and cytotoxicity 
assays. J Immunol Methods 1983;65:55-63.

23. Herrmann M, Lorenz HM, Voll R, Grünke M, Woith W, Kalden JR. A rapid and simple method for the isolation of apoptotic DNA fragments, Nucleic Acids Res 1995;22: 5506-7.

24. Song $\mathrm{D}, \mathrm{Au} \mathrm{JL}$. Isocratic high-performance liquid chromatographic assay of taxol in biological fluids and tissues using automated column switching. J Chromatogr B Biomed Appl 1995;663:337-44.

25. López-Carrillo L, Hernández Avila M, Dubrow R. Chili pepper consumption and gastric cancer in Mexico: a casecontrol study. Am J Epidemiol 1994;139:263-71.

26. Zhang Z, Hamilton SM, Stewart C, Strother A, Teel RW. Inhibition of liver microsomal cytochrome P450 activity and metabolism of the tobacco-specific nitrosamine NNK by capsaicin and ellagic acid. Anticancer Res 1993; 13(6A):2341-6.

27. Miyashita T, Reed JC. Tumor suppressor p53 is a direct transcriptional activator of the human bax gene. Cell 1995; 80:293-9.

28. Modly CE, Das M, Don PS, Marcelo CL, Mukhtar H, Bickers DR. Capsaicin as an in vitro inhibitor of benzo(a)pyrene metabolism and its DNA binding in human and murine keratinocytes. Drug Metab Dispos 1986;14: 413-6.

29. Teel RW. Effects of capsaicin on rat liver S9-mediated metabolism and DNA binding of aflatoxin. Nutr Cancer 1991;15:27-32.

30. Surh YJ, Lee RC, Park KK, Mayne ST, Liem A, Miller JA. Chemoprotective effects of capsaicin and diallyl sulfide against mutagenesis or tumorigenesis by vinyl carbamate and N-nitrosodimethylamine. Carcinogenesis 1995; 16:2467-71.

31. Richeux F, Cascante M, Ennamany R, Saboureau D, Creppy EE. Cytotoxicity and genotoxicity of capsaicin in human neuroblastoma cells SHSY-5Y. Arch Toxicol 1999; 73:403-9.

32. Jung MY, Kang HJ, Moon A. Capsaicin-induced apoptosis in SK-Hep-1 hepatocarcinoma cells involves Bcl-2 downregulation and caspase-3 activation. Cancer Lett 2001;165: 139-45.

33. Lee YS, Nam DH, Kim JA. Induction of apoptosis by capsaicin in A172 human glioblastoma cells. Cancer Lett 2000;161:121-30.

34. Lin MH, Lee YH, Cheng HL, Chen HY, Jhuang FH, Chueh PJ. Capsaicin inhibits multiple bladder cancer cell phenotypes by inhibiting tumor-associated NADH oxidase (tNOX) and Sirtuin1 (SIRT1). Molecules 2016;21:849-62.

35. Yang ZH, Wang XH, Wang HP, Hu LQ, Zheng XM, Li SW. Capsaicin mediates cell death in bladder cancer T24 cells through reactive oxygen species production and mitochondrial depolarization. Urology 2010;75:735-41.

36. Igawa Y, Satoh T, Mizusawa H, Seki S, Kato H, Ishizuka $\mathrm{O}$, et al. The role of capsaicin-sensitive afferents in autonomic dysreflexia in patients with spinal cord injury. BJU Int 2003;91:637-41.

37. de Sèze M, Wiart L, Joseph PA, Dosque JP, Mazaux JM, Barat M. Capsaicin and neurogenic detrusor hyperreflexia: a double-blind placebo-controlled study in 20 patients with spinal cord lesions. Neurourol Urodyn 1998;17:513-23.

38. Sosnik A, Cohn D, San Román J, Abraham GA. Crosslinkable PEO-PPO-PEO-based reverse thermo-responsive gels as potentially injectable materials. J Biomater Sci Polym Ed 2003;14:227-39.

39. Cruz F, Guimarães M, Silva C, Rio ME, Coimbra A, Reis M. Desensitization of bladder sensory fibers by intravesical capsaicin has long lasting clinical and urodynamic effects in patients with hyperactive or hypersensitive bladder dysfunction. J Urol 1997;157:585-9. 